\title{
On the Quest for Defining Organisational Plasticity: A Community Modelling Experiment
}

\author{
Peer-Olaf Siebers ${ }^{1}$, Dinuka B. Herath ${ }^{2}$, Emanuele Bardone ${ }^{3}$, Siavash Farahbakhsh ${ }^{4}$, Peter. G. \\ Knudsen ${ }^{5}$, Jens K. Madsen ${ }^{6}$, Mehwish Mufti ${ }^{7}$, Martin Neumann ${ }^{8}$, Dale Richards ${ }^{9}$, Raffaello Seri ${ }^{10}$, and \\ Davide Secchi ${ }^{11}$ \\ ${ }^{1}$ School of Computer Science, University of Nottingham, UK. \\ ${ }^{2}$ Department of Management, Huddersfield Business School, University of Huddersfield, UK. \\ ${ }^{3}$ Institute of Education, University of Tartu, Estonia. \\ ${ }^{4}$ Faculty of Economics and Management, Free University of Bozen-Bolzano. \\ ${ }^{5}$ Entrepreneur, SMV Partnerinvest, Denmark. \\ ${ }^{6}$ School of Geography and the Environment, University of Oxford, UK. \\ ${ }^{7}$ Bournemouth University, UK. \\ ${ }^{8}$ Institute for Sociology, JGU Mainz, Germany \\ ${ }^{9}$ Department of Engineering, Nottingham Trent University, UK. \\ ${ }^{10}$ DiECO, Università dell'Insubria, Italy, \& Research Centre for Computational \& Organizational \\ Cognition, University of Southern Denmark. \\ ${ }^{11}$ Research Centre for Computational \& Organizational Cognition, University of Southern Denmark.
}

\begin{abstract}
Purpose - This viewpoint article is concerned with an attempt to advance Organisational Plasticity (OP) modelling concepts by using a novel community modelling framework (PhiloLab) from the Social Simulation community to drive the process of idea generation. In addition, we want to feed back our experience with PhiloLab, as we believe that this way of idea generation could also be of interest to the wider EBHRM community.

Design/methodology/approach - We used some workshop sessions to brainstorm new conceptual ideas in a structured and efficient way with a multi-disciplinary group of 14 (mainly academic) participants, using PhiloLab. This is a tool from the Social Simulation community, which stimulates and formally supports discussions about philosophical questions of future societal models by means of developing conceptual agent-based simulation models. This was followed by an analysis of the qualitative data gathered during the PhiloLab sessions, feeding into the definition of a set of primary axioms of a plastic organisation.

Findings - The PhiloLab experiment helped with defining a set of primary axioms of a plastic organisation, which are presented in this viewpoint article. The results indicate that the problem is rather complex but it also shows good potential for an agent-based simulation model to tackle some of the key issues related to OP. The experiment also showed that PhiloLab is very useful in terms of knowledge and idea gathering.

Originality/value - Through information gathering and open debates on how to create an agent-based simulation model of a plastic organisation, we could identify some of the characteristics of OP and start structuring some of the parameters for a computational simulation. With the outcome of the PhiloLab experiment we are paving the way towards future exploratory computational simulation studies of OP.
\end{abstract}

Keywords - Organisational behavior, Plasticity, Disorganisation, PhiloLab, Community modelling, Agent-based modelling

Paper type - Viewpoint

\section{Introduction}

Claims that the external environment of organisations is complex, turbulent, unpredictable, and unstable have been made since the sixties and repeated ever since (Ansoff, 1965; Mintzberg, 1979; Burnes, 2005; Agrawal, 2014). Supporting theories and approaches usually have a macro or strategic take on how organisations adapt in the face of environmental turbulence (Levinthal, 1997). Within this domain, 
a relatively overlooked area of enquiry pertains to the study of how internal organisational processes react, modify, adapt, and evolve as a result of pressures to sudden, unexpected, or continuous change. In other words, adaptation to an external stimulus may bring consequences for organisational internal processes, procedures, working relations, behaviours, structures, and norms, for example. This not only changes individual behaviours and interactions, but it has far reaching implications that can be tracked down to the entire organisation system. This has obvious repercussions on the way people are managed, especially if one considers 'readiness for change' as one of the areas in which Strategic Human Resource Management operates (e.g. Para-González et al., 2019). What are the characteristics of these internal aspects that allow organisations to be malleable enough to adapt to a turbulent environment? How are the macro aspects of strategic adaptability affected by and how do they affect the micro elements within organisations? These questions are at the core of this viewpoint article.

In the extant literature, the precise definition of Organisational Plasticity (OP) is an open question. However, this does not entail a complete lack of understanding nor total disagreement on every facet of the idea. Previous treatments of the topic do converge on some key facets of OP but diverge as to the conceptual boundary as well as the use of the concept towards predefined ends. For instance, Alqithami and Hexmoor (2014, p.567) defined OP as the "property of network organization that affords them rapid change". This definition implies that plasticity is a property of organisations that rapidly adapts to volatile environments. Whether this property is extended to organisations that reside in relatively stable environments is not clear in this conception. It might well be that plasticity is more useful or more pronounced in volatile environments, but such utility does not directly make the phenomenon solely a 'property' of network organisations alone. Levinthal and Marino (2015) envisage a broader conception of OP, where it is not a property of a certain type of organisation but a property that can be seen in all types of organisations. Here plasticity is seen as a phenomenon that provides greater agility in producing variation in organisational adaptation over time. Thus, rather than being tethered to a fixed template of operation, a plastic organisation diversifies its selection of organisational practices (moving away from a set template) over time. These two conceptions of OP further differ from how the phenomenon is instantiated in an organisation. While Levinthal and Marino (2015) see the enactment of OP as a functional choice, Alqithami and Hexmoor (2014) see it both as structural and functional (albeit within network organisations). While the precise conception of OP as pointed out above has some significant difference among contributors, there are also crucial agreements. Most authors in this domain agree (albeit to varying degrees) that, "plasticity goes beyond adaptation issues and includes (a) foundational and (b) structural changes to the organization" (Alqithami and Hexmoor, 2014, p.569). Further, we find, as prior literature would suggest (Bruns and Stalker, 1961; Collis, 1994; Brown and Eisenhardt, 1997; Helfat et al., 2009; Teece, 2007), that plasticity, other things being equal, is more valuable in more dynamic environments. Levinthal and Marino (2015, p.1) go beyond this and suggest that even in environments where OP is desirable, it "entails possible costs in terms of reduced selectability of the underlying trait" as well as having the potential to lessen the reliable replication of behaviours in any environment. However, the extent to which reliability in the replication of behaviours is desired in highly volatile environments remains to be determined. Thus factoring in both areas of convergence and divergence in the extant literature, in very broad terms, OP can be identified as the extent to which the conditions allowing a conservative stretch are in place.

Thus, a tentative definition of a plastic organisation would that of one that is capable of stretching or reducing aspects of its operations with ease, so to adapt both in a timely fashion and repeatedly over time. In addition to that, the depth of change that a plastic organisation can handle may be either large or small. An example could be a business start-up, where urgency and necessity make effectiveness preferred to efficiency. This means that, for example, "getting the job done" is favoured to cutting some slack, reducing costs, or defining standard operating procedures, to timely meet customers' needs. Also, in a business start-up most processes, operations, and even roles and responsibilities are unstable. Under these circumstances, experience together with learning and adaptation are a key component of what "makes or breaks" the enterprise (Murray and Tripsas, 2004). The systemic nature of fluid interactions between the position of an organisation in the market or society, and the various aspects of individuals who cope with complexity, seems to be very important to define OP. Due to the nature of the problem and to the lack of techniques apt to the task, these connections have been vastly overlooked in the literature. This goes to the point that we do not have a theoretical nor an operational definition of this ability that organisations may show to practice fluid adaptability within and outside of 
their boundaries. In other words, the conditions and components of OP are yet to be isolated, understood, and defined.

To better specify the nature of our enquiry, two main assumptions are considered. The first is that there is an obvious connection between micro and macro domains ${ }^{1}$ (Secchi and Cowley, 2018) and that the interplay between these two is such that one shapes and/or affects the other and vice-versa. This means that we are not making any claim about the direction of causality, whether it is top-down or bottom-up. Instead, the organisation is intended as a complex system (Neumann and Secchi, 2016) where its parts are interconnected in a way such that a trigger of change may appear anywhere. Whether this trigger transforms into an enabler (a change-provoking event) depends on the conditions in which the system (i.e. the organisation) finds itself. Now, change related to adaptation is ordinary business for organisations, but an understanding of the mechanisms that allow combinations of micro and macro elements to make room for plasticity are unclear.

The second assumption is that OP requires a loosely structured and less formal way of organising (Fioretti, 2012; Herath et al., 2016). The literature on the connection between disorganisation and adaptability (Herath et al., 2017; Herath, 2019) as well as on disorganisation in general (Abrahamson, 2002; Abrahamson and Freeman, 2007) is particularly slim. However, it is intuitive enough to state that an organisation with fewer (or more relaxed) formal norms, flat hierarchy, and distributed responsibilities may be more capable to confront and manage sequences of change-provoking events. To this, one may also add size and geographical location, together with time in which some events occur, for example, to indicate the fact that we are dealing with a complex system (Edmonds and Meyer, 2017). This also means that these types of problems cannot be studied by closed-form analytical solutions but they require a more adaptive dynamic approach, provided by computational models (Madsen et al., 2019). One such approach is agent-based computational simulation modelling (shortly, ABM), a method that allows to study complexity as it applies to interacting elements that behave, think, and act, according to rules in a given environment (e.g., Siebers et al., 2008; Edmonds and Meyer, 2017; Secchi and Neumann, 2016).

These two assumptions - namely, the connection between micro and macro aspects of adaptation, and the extent to which a plastic organisation is or is not simply facing disorganisation-constitute the way in which we intend to address the questions raised at the beginning of this viewpoint article regarding the characteristics of OP and the interplay between macro aspects of strategic adaptability and micro elements of an organisation.

From this brief introduction, we are left with two major points of enquiry. On the one hand, there is still a need to better understand what the definition of OP presented above really entails. On the other hand, its impact and effects are yet to be explored.

This viewpoint article presents results of a community modelling experiment that fulfilled the purpose of stimulating a discussion on OP amongst the participants of the Agent-Based Models of Organisational Behaviour 3 (ABMO3) Workshop (January 2018). That helped participants look at the topic from different angles and we believe that this viewpoint article can serve a similar purpose for those who seek an introduction to the topics developed further in this Special Issue. We would like to note that the community modelling experiment essentially is a qualitative technique, i.e. lessons are generated through several focus groups, and there is no quantitative component displayed in this manuscript. This may be at odds with EBHRM's positioning and thus could be perceived as unusual from the readership of this journal. For this reason, this viewpoint article is meant as an opening piece setting the ground for the remainder of the Special Issue, where ABMs and their results are presented. The lessons generated in this viewpoint article are of value for two communities: (a) those scholars interested in OP and (b) those scholars interested in methods that can help to design ABMs.

\section{A community modelling experiment with PhiloLab Methodological basis}

\footnotetext{
${ }^{1}$ The difference between micro and macro is, according to Secchi and Cowley (2018), very clear in organisation research. Individual-centered approaches, for example, those attributable to the Carnegie School (Simon, March, Olsen, Gavetti, Levinthal, and others; see Gavetti et al., 2007) and most streams of Weick's sensemaking (Weick, 1993), are interested in micro phenomena that start and end with the self. The macro domain is, instead, a broad perspective that deals mostly with systemic effects, attributable to the organizational super-structure (e.g., culture, processes, standards, norms).
} 
The idea for this experiment stems from an ESSA@work ${ }^{2}$ workshop, where PhiloLab was proposed by Siebers (2017). PhiloLab is a concept based on the Engineering Agent-Based Social Simulation (EABSS) framework. While the purpose of the EABSS framework is model development and documentation in the context of Social Simulation, Siebers (2017) was interested in testing the framework's capabilities as a communication and idea generation tool in the context of Organisational Behaviour; for this application it was named PhiloLab. PhiloLab stimulates and formally supports discussions about philosophical questions of future societal models, by providing the means for using a guided conversation to capture the diversity of perspectives held by the various stakeholders on a specific topic (Siebers, 2019). Therefore, the only difference between the EABSS framework and PhiloLab is their purpose and consequently their outcome focus (i.e. the information that will be captured and how it is used later) - technically they are the same. In the PhiloLab experiment we wanted to see how the idea presented in ESSA@work could be executed to help better understand what OP is, how it is embedded in organisational processes, and how we could model it. Here we feed back our experience on using the PhiloLab concept as a communication and idea generation tool for novel research on OP.

The EABSS framework is designed to support single and multi-disciplinary model development and documentation of human-centric and human-natural systems (full details can be found in Siebers and Klügl, 2017). It is grounded on the concept of co-creation (Mitleton-Kelly, 2003) and ideas from Software Engineering. It uses focus group discussions, predefined table templates, and the Unified Modelling Language (UML), a graphical notation used in Software Engineering to conduct system analysis and design (Fowler, 2004), as the main forms of stimulating and documenting contributions during problem analysis and model development. The framework could also be equated to the User Centred Design approach used in Human Factors, which follows similar principles, although the main focus is on placing the user in the middle of the design process (Norman and Draper, 1986). The EABSS framework, depicted in Figure 1, consists of three components: "Analysis", "Design", and "Knowledge Gathering".

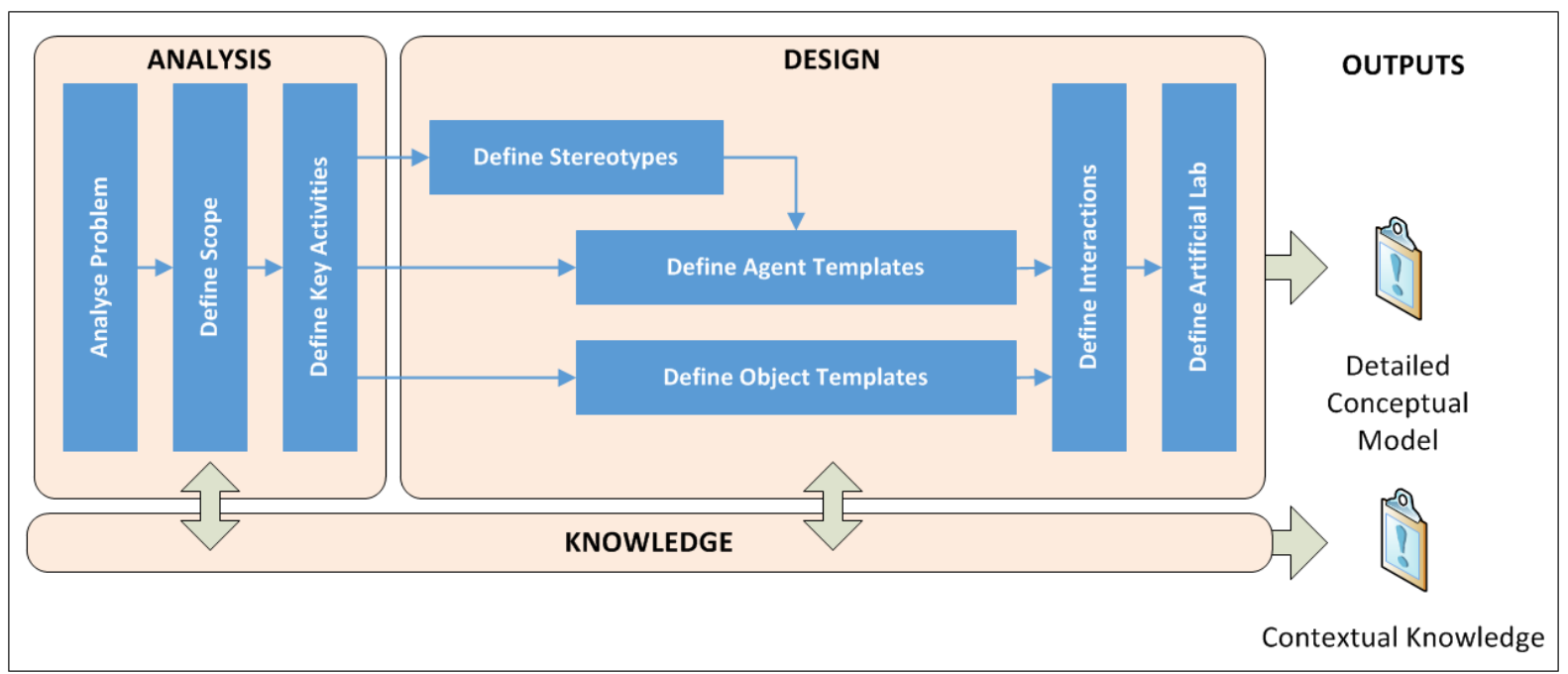

Figure 1: The EABSS framework and its outputs (adapted from Siebers and Klügl, 2017)

The Analysis component is split into three main steps: problem analysis (consisting of defining the purpose of the model, objectives + hypotheses, experimental factors and responses), model scope definition, and the definition of key activities to be considered. The Design component consists of four main steps: defining stereotypes (attributes and habits of agents), defining agent and object templates (to capture states, behaviours, and decision making processes), defining the interactions amongst agents and between agents and objects, and defining an artificial lab (i.e. the infrastructure for conducting the experiments). Knowledge gathering happens throughout the model development, potentially prior or after a specific step (from the literature or through qualitative data collection) but,

\footnotetext{
${ }^{2}$ ESSA is the European Social Simulation Association and the workshop mentioned in the text is one of the events that the association sponsors throughout the year, outside of their annual conference.
} 
specifically, during a specific step through focus group brainstorms (and discussions, where appropriate). The outcome at the end of the process is twofold. On the one hand, one receives a very detailed conceptual model, which provides a strong basis for an implementation as a social simulation model. On the other hand, one receives some contextual knowledge in form of observations of differences in the views of different domains (e.g., differences in terminology used or methodological approaches applied), differences in relevance of facts for individual participants, etc.

The EABSS framework is designed with the aim to look at a system in more detail with every further step. There is always information from previous steps that can be used to get started with the next step. This principle serves validation, as getting stuck in the current step is a good indicator that something in previous steps is not quite right and needs to be amended.

\section{The experiment}

The PhiloLab experiment was a live experiment carried out during the Agent-Based Models of Organisational Behaviour 3 (ABMO3) Workshop in January 20183, involving all 14 presenters of the workshop, with the goal of building multidisciplinary agent-based models together. Participants were all experienced agent-based modellers who came from different disciplinary backgrounds, including applied statistics, economics, psychology, computer science, organisational behaviour, management, sociology, and one business executive manager. A diversity of career stages and interests were also represented, together with a variety of European university affiliations. Abstracts for ABMO3 were selected with the goal to discuss plasticity in organisations. At the workshop we ran two focus groups. We provided the same aim to both groups: "To investigate what differentiates a plastic organisation setup from a conventional organisation setup". The purpose of the exercise was to start getting a multidisciplinary group of people to talk about the topic and to come up with some interesting research ideas. We had some time constraints. Overall we had four hours spread over two consecutive days. There was an initial presentation to explain the idea behind PhiloLab (30 minutes), two focus group sessions (90 minutes each), and a final session to present preliminary results (30 minutes). From previous experience we knew that it requires about eight hours to comfortably go through the complete process described in the EABSS framework, so with the given time constraints we did not expect to make it through all the steps defined in the framework but we expected to still outline a few relevant modelling concepts. After the first focus group session both groups ended up with an initial scope table and after the second focus group session both groups ended up with an initial design of agent and object templates. It was interesting to see that both groups ended up at the same step, although no pressure was put on the focus group moderators to reach a specific step.

In order to interpret results, we collected the notes from facilitators and audio recorded all the sessions. The final 30-minute discussion was also a way to assess whether the summary was consistent with group members' recollections of the work in the focus groups.

From the engagement and atmosphere during the sessions one could see that people were enjoying the exercise and the overall feedback from the participants after each of the two main sessions was consistently positive. After a short learning period (participants needed some time to understand the fact that the initial focus is on information gathering rather than on debates), all participants contributed equally, and no fights over decisions occurred. From time to time the moderators had to gently move participants to the next step, or remind them on the goals agreed in the problem analysis step, to make sure the resulting modelling activities were in line with the modelling aim, but this all went quite smoothly.

\section{Short summary of findings ${ }^{4}$}

Throughout the experiment we captured a wide range of information from different perspectives, by having the two focus groups led by different types of experts: (1) A PhiloLab expert with very limited knowledge about plastic organisations and (2) two plastic organisation experts with very limited knowledge about PhiloLab. After the exercise we ended up with two completely different models, which provided a very broad aim for the exercise, as expected initially, and as suggested by different types of

\footnotetext{
${ }^{3}$ The workshop was held at the Business School, University of Huddersfield (UK) and was sponsored by the European Academy of Management (EURAM). Further details are available at https://sites.google.com/view/abmworkshops.

${ }^{4}$ Due to the usual constraints of a journal article, we have reported the activities of the two groups in an online webpage called Supplementary Materials, available at https://sites.google.com/view/abmworkshops/EBHRM SM.
} 
experts leading the focus groups. In addition, the exercise delivered a useful collection of contextual knowledge, including a glossary of terms.

The first group used a "concrete" route of exploration and adopted a comparative case study approach, juxtaposing two hypothetical restaurant chains, one that adopted the ideas of OP and one that worked with a more traditional organisational setup. Using a case study made it easy for everyone to relate to something more realistic and to contribute own experiences and innovations during information collection. Furthermore, this group decided to focus on operationalising plasticity in an organisation, to deal with the limited time that was available and to explore the practical implications in implementing OP.

The second group used an "abstract" route of exploration, looking at the system from a more theoretical and highly abstract perspective. The idea was that of interpreting plasticity qua adaptability, hence starting from an external "shock" or stimulus that would impact an organisation. These macro event effects would then be absorbed differently depending on organisational characteristics (e.g., internal structure, role distributions, norms, culture). The group also assumed that the external shock event would evolve while the organisation attempts at dealing with it. This implies that a plastic organisation is composed of workers that are capable of diagnosing the implications of a shock and of monitoring its potential future impacts. The discussion also indicated that the network of formal and informal relationships within an organisation might play a significant role in identifying degrees of plasticity (see below for further details on how this is intended).

\section{Feeding an agent-based model}

Through the discussions in the PhiloLab sessions it was determined that, when considering how a model based on OP is built, there are some key questions that need to be answered. These are: (a) What differentiates plastic organisations from other organisations? (b) What elements need to be considered when making an organisation "plastic"? Both of these questions are highly relevant when considering the heightened dynamism required by modern organisations to deal with both internal and external pressures (Eller et al., 2016). Evidence shows that such complexities, if unaddressed, invariably lead to a high rate of business mortality (Reeves et al., 2016). One of the root causes for this increase in organisational mortality is the inability of organisations and managers alike to adapt to these highly demanding complexities (Reeves and Deimler, 2011). Therefore, through this ABM we attempt to explore how plasticity may lead to higher organisational adaptability, and consequently a lower rate of business mortality.

In tackling the first question (a), we used the formalisation continuum by Cohen et al. (1972) and its subsequent adaptations (Fioretti and Lomi, 2008; Herath et al., 2016) as a starting point. As depicted in Figure 2, one end of the spectrum (A) constitutes complete anarchy while the other end depicts complete hierarchy (B). Both the extremes $A$ and $B$ are logical end points in the continuum but are not representative of the modern world. For instance, an organisation cannot function with complete anarchy, where all workers' goals are completely mutually exclusive, with no organisational boundaries or cohesion (Cohen et al., 1972). Likewise, a completely formal organisation is equally unlikely, especially when considering that there are no organisations where every employee's goals are aligned directly with the organisation's goals. In reality, modern organisations fall somewhere in between the two extreme ends of the spectrum. In this continuum the level of formalisation is based on structural and functional elements of the organisation (Herath et al., 2017). The structure in this case refers to the manner in which the organisation is set up in terms of lines of command, information flow and power dynamics. Function in this case refers to the rules of interaction the workers within the organisation have to abide by. By interpreting what we wrote above under these lenses, we may claim that a plastic organisation would need the flexibility to re-define its functional scope, while keeping aspects of its structure. Hence, OP is more likely placed closer to point $A$ than to point $B$ in the spectrum.

\section{Anarchy/Complete Disorganisation}

A
Hierarchy/Complete

Organisation

B

Figure 2: Formalisation continuum 
Let's turn our attention to the second question (b). Even though Figure 2 provides some insight on how a plastic organisation can be differentiated from non-plastic organisations through the formalisation dimension (a possible parameter in a model) it is not sufficient in encapsulating the concept of plasticity fully. Therefore, while a plastic organisation ought to be less formalised there are a few other elements which need to be considered. Based on the extant literature (Levitt and March, 1995; Frank et al., 2017) one key facet of plasticity is an organisation's ability to adapt to both internal and external stimuli while preserving its core identity. The identity here refers to the core business functions of the organisation. It is also envisaged that plastic organisations are more explorative and opportunistic in dealing with stimuli than organisations which are non-plastic (Andren et al., 2003). Based on this, the following starting axioms presented in Table I can be defined for a model of plasticity.

Table I: Primary axioms of a plastic organisation: preliminary sketch for a model (blue text indicates types of disorganisation while red text relates more directly to plasticity)

\begin{tabular}{cll}
\hline Point & \multicolumn{1}{c}{ Characteristic } & \multicolumn{1}{c}{ Description } \\
\hline A $\quad$ Higher functional disorganisation & $\begin{array}{l}\text { A plastic organisation has relatively low functional } \\
\text { boundaries imposed on workers (in terms of rules and } \\
\text { procedures) in seeking and engaging organisational } \\
\text { tasks. }\end{array}$ \\
B $\quad$ Higher structural disorganisation & $\begin{array}{l}\text { The hierarchical set up of the organisation is relaxed } \\
\text { to a point where workers can easily interact between } \\
\text { hierarchical levels and power structures, while having } \\
\text { open access to all the relevant information required for } \\
\text { effective task completion. }\end{array}$ \\
C $\quad \begin{array}{l}\text { Preservation of its core identity } \\
\text { while adapting to internal and } \\
\text { external stimuli }\end{array}$ & $\begin{array}{l}\text { While the organisation might change its operations } \\
\text { and the level of formalisation, the core competencies, } \\
\text { values, vision, and mission of the organisation are } \\
\text { preserved. }\end{array}$ \\
D Higher opportunity seeking & $\begin{array}{l}\text { Depending on the opportunities available plastic } \\
\text { organisations will change their operations to engage } \\
\text { with as many relevant opportunities as possible. }\end{array}$ \\
characteristics & $\begin{array}{l}\text { Plastic organisations will use explorative strategies } \\
\text { throughout their operations in order to constantly } \\
\text { assess opportunities available both internally and } \\
\text { externally. }\end{array}$ \\
\hline
\end{tabular}

It should be noted that the axioms discussed in Table I are partly an outcome of the PhiloLab experiment. Also, given the exploratory nature of this exercise, more research is required in order to determine if the aforementioned axioms are sufficient for a comprehensive model of plasticity. As a way forward, for example, one should be able to discriminate against organisation size, location, time, and industry. In fact, very different dynamics may be in place depending on these (and other) structural elements. Nevertheless, the axioms in Table I provide a starting point for developing an ABM of plasticity. It is interesting to notice that the two teams converged on some common elements of plasticity. This was a significant development given that the two teams had different starting points, different outlooks on the topic, varying levels of experience and, ultimately, different models. Despite these differences, both groups arrived at a somewhat common and shared understanding of what "plasticity should be constituted of" as captured in Table I.

In the aforementioned axioms the term 'high' is used in relation to conventional set ups. For instance, if we consider point $A$; an organisation with high functional disorganisation is a firm which actively seeks to reduce organisational rules and procedures in order to enable employees to interact freely when engaging in problem solving. This therefore moves away from traditional highly compartmentalised organisational set ups and actively encourages fluid participation (high inter team/department collaboration). Therefore, if a firm exhibits such characteristics we can objectively define them as highly functionally disorganised. The remaining axioms are defined similarly. 
Upon defining the starting axioms, it could be then determined how best to model plasticity in an agent-based environment. Keeping in line with the need for modern organisations to be adaptable to external and internal stimuli, we envisage a model which has two environmental conditions (namely, ORG1 and ORG2). Condition ORG1 and condition ORG2 can be seen as two different organisations. ORG1 is more plastic than ORG2, where ORG1 is modelled on the basis of all the axioms discussed in Table I while ORG2 is not. Each of the environments will have two types of agents, namely workers and tasks. The workers here refer to the employees within the organisation and can be differentiated based on job role (i.e. low level workers, middle managers, top management). The task will be the internal and external stimuli which the workers will have to deal with. Each worker or group of workers has a limited time to deal with the task, mirroring how tasks are actually handled differently. Each task will also have a level of complexity. Both conditions ORG1 and ORG2 will have the same set of tasks. The model can then be developed in a manner where it will provide the researchers the capability of observing the differences between condition ORG1 (plastic condition) and ORG2 (non-plastic condition). This also provides some insight into which condition is more adaptable to internal and external pressures.

\section{Lessons learned and concluding remarks}

At the current juncture, the model is at its most basic specification and has some unanswered questions. First, it is not clear if the axioms currently determined are enough to encapsulate OP. It may be the case that more axioms are required. Second, while comparing the two conditions discussed above may provide some indication as to the differences of plastic and non-plastic systems, it does not clearly take context into account. Finally, through the PhiloLab discussion there were a few key concepts such as docility - a socially-based cognitive attitude that is used to study how employees interact and make decisions (Secchi and Bardone, 2009; Bardone and Secchi, 2017; Secchi, 2011)—which were left out in the initial development of the model to fully concentrate on plasticity. In light of the discussion above, it might be worth revisiting some of these concepts in order to improve the granularity of the agents which the model (i.e. workers and tasks). While many open questions are still unanswered, having a starting point akin to the model outlined here is useful for the steps necessary to move this research forward.

There are also some lessons learned in regards to the use of PhiloLab and they can be summarised in the following points. First, one should be aware that the main creative energy is unleashed in the problem analysis steps. However, one also needs to consider that problem analysis takes quite a substantial amount of time. Therefore, depending on the ultimate goal and time constraints, there are two strategies for running PhiloLab experiments. One concerns the case when focus groups are run in parallel and they are provided only with the same broad aim to base their model development on, then it is very likely that they end up with very diverse and innovative models. Some of this diversity may converge or diverge even more when a complete PhiloLab walk-through can be managed. Unfortunately, we had some time constraints and only got about half way through the steps, but interestingly we identified some convergence in our analysis of the outcome of both focus groups at an abstract level, although the detailed conceptual models were substantially different. The other relates to the case when focus groups are run in parallel and a complete problem analysis (including everything from aim to responses) is initially provided, then it is very likely that one ends up with similar models that are also in line with what one would expect as focus group moderator. This is ideal when one is in need of in-depth understanding of a specific topic or when one is in need for inputs for a specific model. It is also a useful strategy to consider, in case one has limited time but wants to get through the complete PhiloLab walk-through. Second, group adaptation is not an issue. In the workshop we had participants who could only stay for the first session and others who joined only for the second session. This did not cause any problems, as previous work could be easily explained thanks to the produced documentation (i.e. the structured notes, tables, and UML diagrams). Third, when initially explaining the concept of PhiloLab to participants, one should use an example that is not directly related to the topic that is going to be discussed, so that people do not confound the results later. Once the model development process has been completed, it would be good to show the participants some concrete output (so that they see some value in their participation). As it is often impossible to show an implementation of the model that was developed at the end of a workshop, it would be good to show them an implementation of the example that was presented in the introductory session. In this way the 
participants get at least a feeling for how a potential implementation of their own model would look like, and are more likely to participate in following events.

This viewpoint article presents some initial approaches towards ABM for an exploratory simulation model designed to understand and define OP and its consequences. The work was conducted using an experiment in community modelling through the PhiloLab concept. Results indicate that the problem is rather complex but it also shows good potential for a simulation model to tackle some of the key issues related to OP. There is still a lot of work to do as we are just at the beginning of understanding OP. Examples about the use of ABM for better understanding OP can be found in the remainder of this special issue. For this viewpoint article, regarding research on OP, the next step will be to further debate the outcome from the community modelling experiment with all relevant stakeholders (including managers, employees, entrepreneurs, etc.). Regarding the use of PhiloLab, it should be fine-tuned to meet the specific requirements of the Organisational Behaviour domain. It would also be good to produce a user guide and some examples, so that it is easier to understand how to use it. We aim, over time, to provide an online library of use cases to help the novice focus group moderator to better understand how to use PhiloLab and to feel confident in the role of focus group moderator. Overall, the positive experience of the community modelling experiment encouraged all of us to adopt PhiloLab as a conceptualisation method for Organisational Behaviour ABMs and we aim to continue using it for conceptualisation and idea generation in future research.

\section{Acknowledgments}

We wish to thank the Business School at the University of Huddersfield for hosting the ABMO3 Workshop, and the European Academy of Management (EURAM) that kindly co-funded and sponsored the event. An earlier version of this viewpoint article has been presented to the annual conference of the European Social Simulation Association, the Social Simulation Conference (SSC) 2018 in Stockholm, Sweden. We wish to thank the conference participants and reviewers for useful constructive feedback.

\section{References}

Abrahamson, E., 2002. Disorganization theory and disorganizational behavior: Towards an etiology of messes. Research in Organizational Behavior, 24, pp.139-180.

Abrahamson, E. and Freedman, D.H., 2007. A Perfect Mess: The Hidden Benefits of Disorder. Little Brown, New York, NY.

Agrawal, P., 2014. Effect of uncertain and turbulent environment on organizational design. Economic \& Business Journal, 5(1), pp.11-24.

Alqithami, S. and Hexmoor, H., 2014. Plasticity in network organizations. Journal of Advanced Computational Intelligence and Intelligent Informatics, 18(4), pp.567-572.

Andren, L., Magnusson, M. and Sjolander, S., 2003. Opportunistic adaptation in start-up companies. International Journal of Entrepreneurship and Innovation Management, 3(5-6), pp.546-562.

Ansoff, H.I., 1965. Corporate Strategy. McGraw-Hill, New York, NY.

Bardone, E. and Secchi, D., 2017. Inquisitiveness: Distributing rational thinking. Team Performance Management: An International Journal, 23(1/2), pp.66-81.

Brown, S.L. and Eisenhardt, K.M., 1997. The art of continuous change: Linking complexity theory and time-paced evolution in relentlessly shifting organizations. Administrative Science Quarterly, pp.1-34.

Bruns, T. and Stalker, G.M., 1961. The Management of Innovation. Tavistock, London, pp.120-122.

Burnes, B., 2005. Complexity theories and organizational change. International Journal of Management Reviews, 7(2), pp.73-90.

Cohen, M.D., March, J.G. and Olsen, J.P., 1972. A garbage can model of organizational choice. Administrative Science Quarterly, 17(1), pp.1-25.

Collis, D.J., 1994. Research note: How valuable are organizational capabilities?. Strategic Management Journal, 15(S1), pp.143-152.

Edmonds, B. and Meyer, R. (Eds.), 2017. Simulating Social Complexity. A Handbook, 2e. Springer, New York, NY. 
Eller, F.J., Fischer, S. and Diedrich, L., 2016. Managing (in) times of uncertainty: The effects of leadership sensemaking on employee well-being in dynamic business environments. Wiencke, M., Cacace, M. and Fischer S. (Eds.) Healthy at Work, Springer, Cham, pp.127-137.

Fioretti, G., 2012. Two measures of organizational flexibility. Journal of Evolutionary Economics, 22(5), pp.957-979.

Fioretti, G. and Lomi, A., 2008. An agent-based representation of the garbage can model of organizational choice. Journal of Artificial Societies and Social Simulation, 11(1), p.1.

Fowler, M., 2004. UML Distilled: A Brief Guide to the Standard Object Modeling Language, 3e. Addison-Wesley Professional.

Frank, H., Güttel, W. and Kessler, A., 2017. Environmental dynamism, hostility, and dynamic capabilities in medium-sized enterprises. The International Journal of Entrepreneurship and Innovation, 18(3), pp.185-194.

Gavetti, G., Levinthal, D. and Ocasio, W., 2007. Perspective-Neo-Carnegie: The Carnegie school's past, present, and reconstructing for the future. Organization Science, 18(3), pp.523-536.

Helfat, C.E., Finkelstein, S., Mitchell, W., Peteraf, M., Singh, H., Teece, D. and Winter, S.G., 2009. Dynamic Capabilities: Understanding Strategic Change in Organizations. John Wiley \& Sons.

Herath, D., 2019. Business Plasticity Through Disorganization. Emerald Publishing.

Herath, D., Costello, J. and Homberg, F., 2017. Team problem solving and motivation under disorganization-an agent-based modeling approach. Team Performance Management: An International Journal, 23(1/2), pp.46-65.

Herath, D., Secchi, D. and Homberg, F., 2016. Simulating the effects of disorganisation on employee goal setting and task performance. Secchi, D. Neumann, M. (Eds.), Agent-Based Simulation of Organizational Behavior. New Frontiers of Social Science Research, Springer, Cham, pp. 63-84.

Levinthal, D.A., 1997. Adaptation on rugged landscapes. Management Science, 43(7), pp.934-950.

Levinthal, D.A. and Marino, A., 2015. Three facets of organizational adaptation: Selection, variety, and plasticity. Organization Science, 26(3), pp.743-755.

Levitt, B. and March, J.G., 1995. Chester I. Barnard and the intelligence of learning. Williamson, O.E. (Ed.), Organization Theory: From Chester Barnard to the Present and Beyond, 2e. Oxford University Press.

Madsen, J.K., Bailey, R., Carrella, E. and Koralus, P., 2019. Analytic versus computational cognitive models: Agent-based modeling as a tool in cognitive sciences. Current Directions in Psychological Science, 28(3), pp.299-305.

Mintzberg, H., 1979. The Structuring of Organizations, Prentice-Hall, Englewood Cliffs, NJ.

Mitleton-Kelly, E., 2003. Complexity research-approaches and methods: The LSE Complexity Group integrated methodology, Keskinen, A., Aaltonen, M. and Mitleton-Kelly, E. (Eds.), Organisational Complexity. Tutu Publications. Finland Futures Research Centre, Turku School of Economics and Business Administration, Turku, Finland, pp. 56-77.

Murray, F. and Tripsas, M., 2004. The exploratory processes of entrepreneurial firms: The role of purposeful experimentation. Baum, J.A. and McGahan, A.M. (Eds.), Business Strategy over the Industry Lifecycle, Volume 21 of Advances in Strategic Management, Emerald Publishing, pp. 45-75.

Neumann, M. and Secchi, D., 2016. Exploring the new frontier: Computational studies of organizational behavior. Secchi, D. and Neumann, M. (Eds.) Agent-Based Simulation of Organizational Behavior, Springer, Cham, pp. 1-16.

Norman, D.A. and Draper, S.W., 1986. User Centered System Design: New Perspectives on HumanComputer Interaction, L. Erlbaum Associates, Broadway, Hillsdale, NJ.

Para-González, L., Jiménez-Jiménez, D. and Martínez-Lorente, Á.R., 2019, Do SHRM and HPWS shape employees' affective commitment and empowerment?. Evidence-based HRM, 7(3), pp.300-324.

Reeves, M. and Deimler, M., 2011. Adaptability: The new competitive advantage. Harvard Business Review, 89(7-8), pp. 135-141

Reeves, M., Levin, S. and Ueda, D., 2016. The biology of corporate survival: Natural ecosystems hold surprising lessons for business. Harvard Business Review, 94(1-2), pp.46-56.

Secchi, D., 2011. Extendable Rationality: Understanding Decision Making in Organizations. Springer Science \& Business Media. 
Secchi, D. and Bardone, E., 2009. Super-docility in organizations: An evolutionary model. International Journal of Organization Theory and Behavior, 12(3), pp.339-379.

Secchi, D. and Cowley, S.J., 2018. Modeling organizational cognition: The case of impact factor. Journal of Artificial Societies and Social Simulation, 21(1),13.

Secchi, D. and Neumann, M. (Eds.), 2016. Agent-Based Simulation of Organizational Behavior. New Frontiers of Social Science Research. Springer, Cham.

Siebers P.O., 2019. Community modelling and communication with PhiloLab, presented at the AgentBased Models in Philosophy - Prospects and Limitations Workshop, 20-22 Mar, Bochum, Germany, extended abstract available at http://www.cs.nott.ac.uk/ pszps/docs/pos-ABMPhil2019v01 extendedAbstract.pdf (last accessed 23/08/2020)

Siebers, P.O. and Aickelin, U., 2008. Introduction to multi-agent simulation. Adam, F. and Humphreys, P. (Eds.), Encyclopedia of Decision Making and Decision Support Technologies, IGI Global, pp. 554-564.

Siebers, P.O., 2017. PhiloLab: An artificial lab to investigate philosophical questions, presented at ESSA@work Simulation Workshop, 23-24 Nov, Hamburg, Germany.

Siebers, P.O. and Klügl, F., 2017. What software engineering has to offer to agent-based social simulation. Edmonds B. and Meyer, R. (Eds.), Simulating Social Complexity. A Handbook, 2e, Springer, New York, NY, pp.81-117.

Teece, D.J., 2007. Explicating dynamic capabilities: The nature and microfoundations of (sustainable) enterprise performance. Strategic Management Journal, 28(13), pp.1319-1350.

Weick, K.E., 1993. The collapse of sensemaking in organizations: The Mann Gulch disaster. Administrative Science Quarterly, pp.628-652. 